Reihe Ökonomie Economics Series

\title{
The Intergenerational Overlap and Human Capital Formation
}

Oded Stark, Yong Wang 
Reihe Ökonomie Economics Series

\section{The Intergenerational Overlap and Human Capital Formation}

Oded Stark, Yong Wang

March 2004

Institut für Höhere Studien (IHS), Wien Institute for Advanced Studies, Vienna 


\section{Contact:}

Oded Stark

University of Bonn

Walter-Flex-Strasse 3

D-53113 Bonn, GERMANY

email: ostark@uni-bonn.de

and

University of Vienna

Yong Wang

City University of Hong Kong

Founded in 1963 by two prominent Austrians living in exile - the sociologist Paul F. Lazarsfeld and the economist Oskar Morgenstern - with the financial support from the Ford Foundation, the Austrian Federal Ministry of Education and the City of Vienna, the Institute for Advanced Studies (IHS) is the first institution for postgraduate education and research in economics and the social sciences in Austria. The Economics Series presents research done at the Department of Economics and Finance and aims to share "work in progress" in a timely way before formal publication. As usual, authors bear full responsibility for the content of their contributions.

Das Institut für Höhere Studien (IHS) wurde im Jahr 1963 von zwei prominenten Exilösterreichern dem Soziologen Paul F. Lazarsfeld und dem Ökonomen Oskar Morgenstern - mit Hilfe der FordStiftung, des Österreichischen Bundesministeriums für Unterricht und der Stadt Wien gegründet und ist somit die erste nachuniversitäre Lehr- und Forschungsstätte für die Sozial- und Wirtschaftswissenschaften in Österreich. Die Reihe Ökonomie bietet Einblick in die Forschungsarbeit der Abteilung für Ökonomie und Finanzwirtschaft und verfolgt das Ziel, abteilungsinterne Diskussionsbeiträge einer breiteren fachinternen Öffentlichkeit zugänglich zu machen. Die inhaltliche Verantwortung für die veröffentlichten Beiträge liegt bei den Autoren und Autorinnen. 


\section{Abstract}

We propose a new microeconomic explanation for the divergent experiences of economies in forming human capital. We suggest that the positive effect of a longer life expectancy on human capital formation arises from two separate effects: a life-expectancy effect and a prolonged intergenerational overlap effect. We argue that the duration of the overlap between generations and the associated parental support can affect the marginal cost of human capital formation and hence its level: parental support is cheaper than market financing. We thus attribute the strong correlation between the formation of human capital and life expectancy not merely to a higher marginal benefit arising from a longer payback period but also to a lower marginal cost arising from a prolonged intergenerational overlap. We provide conditions under which a longer overlap results in a higher level of per-capita output.

\section{Keywords}

Duration of intergenerational overlap; Parental support; Human capital formation; Social welfare

\section{JEL Classification}

D91; J24 


\section{Comments}

Partial financial support from the Humboldt Foundation and the Sohmen Foundation is gratefully acknowledged. 


\section{Contents}

$\begin{array}{ll}\text { 1. The idea } & 1\end{array}$

2. The analytical framework 3

3. The effect of an extended intergenerational
overlap on human capital formation

4. The welfare effect of an extended intergenerational overlap

5. Complementary reflections 13

$\begin{array}{ll}\text { Appendix } & 16\end{array}$

$\begin{array}{ll}\text { References } & 17\end{array}$ 


\section{The idea}

It is well recognized that the stock of human capital affects the level of per-capita output in an economy. Whether the effect arises because human capital is an ordinary input in the economy's production function or because the effect manifests itself through the enhancement of total factor productivity (in that it leads to the creation, adoption, implementation, and diffusion of new technologies) are largely empirical issues. The notion that an economy that forms a large quantity of human capital will have a higher per-capita output than an economy that forms a small quantity of human capital can safely be taken as given, requiring little, if any, additional inquiry. But why is it that one economy has, or forms, abundant per-capita human capital, while another has, or forms, little? Why does the percapita human capital gap between economies not close? Much - though not all - of the human capital in an economy is the result of decisions made by individuals. Clearly, several factors are involved and one of them is life expectancy: a longer life expectancy entails a longer payback period that, in turn, encourages larger investments in human capital. An economy consisting of individuals with a long life expectancy will then form more human capital than an economy consisting of individuals with a short life span.

The impact of a lengthened life expectancy comes from the returns side of the human capital investment calculus: the marginal benefit is higher. We argue however, that typically, a lowered marginal cost of forming human capital is imbedded in a lengthened life expectancy. We seek to unearth this effect and study its role in accounting for the divergent experiences of economies in the formation of human capital. We suggest that the lowered marginal cost effect arises from a correlate of extended life expectancy: prolonged duration of the overlap between generations. Suppose that as long as they are alive, parents support the human capital formation of their children, and that the parental support is cheaper than market financing. ${ }^{1}$ An extended life expectancy that results in a prolonged overlap entails more parental support, which in turn can foster the formation of more human capital. An example will serve to illustrate.

Suppose that life expectancy is 45 . An individual gives birth to one child when the individual is 20 years of age. The child is cared for in his infancy and for as long as he

\footnotetext{
${ }^{1}$ We Assume that the technology of human capital formation is invariant to the method of financing; the edge of parental support over market financing arises not from parents' direct involvement in the formation of human capital by their children, but from the intergenerational transfer constituting a means of financing human capital acquisition that is less expensive than the market-based means of financing.
} 
engages in acquiring human capital, conditional on the individual being alive. The age at which the child makes the human capital formation decision is 15. At this age, if the child were to engage in human capital formation, the child could expect parental support for up to 10 years. If the child finds it optimal to devote more than 10 years to human capital formation, he can do so by borrowing at a fixed market interest rate. When the child reaches the age of 20 , he gives birth to a child whom he, in turn, will support in the same manner in which he was supported. Suppose that the child finds it optimal to acquire human capital for a little more than 10 years, say for $\tau$ years in excess of 10. During these years the child has to bear the entire cost of forming human capital, which includes the market rate of interest.

Suppose now that life expectancy is 55 . Retaining all other assumptions as before, the child can now expect parental support for up to 20 years. To see the implications of this assumption for human capital formation, consider the case $0<\tau<10$. All of the years of human capital formation previously financed by commercial loans now become parentally supported, interest-free years. Since the marginal cost of forming human capital goes down, more human capital will be formed. This effect is separate from the returns to human capital, a marginal benefit that arises from the addition of years during which returns to the human capital investment can be reaped. ${ }^{2}$

In section 2 we present our analytical framework. In section 3 we formally investigate the effect of extended overlapping on the formation of human capital by optimizing individuals. To this end we decompose the "gross" life-expectancy effect into a "net" lifeexpectancy effect and an overlapping effect. In section 4 we trace the welfare implication of extended overlapping for an economy that is subjected to such a change. In section 5 we further explain the rationale underlying our idea and offer a suggestion as to how to differentiate empirically between the overlapping model of human capital formation and the received model of human capital formation.

\footnotetext{
${ }^{2}$ To a child at the age of 15 , the expected overlap with a parent whose age is 35 is best given by the contemporaneous life expectancy of adults at the age of 35 rather than by the life expectancy of the parental generation at birth. Life expectancy at birth is quite sensitive to the incidence of children dying at very early ages. Historically, life expectancy was increased through reductions in the number of children dying during infancy and the sharp increases in life expectancy at birth were not followed by corresponding increases in longevity, although the two measures were positively correlated. Since in this paper our interest is in the effect of changes in the life span of adults, that is, in changes in the mean age of death beyond infancy, our reference to life expectancy in the sections that follow should be understood as life expectancy net of the effect of infant mortality.
} 


\section{The analytical framework}

Consider a continuous overlapping-generations economy. At every instant of time a generation is born. A generation consists of a continuum of individuals of measure $N$. The lifespan of an individual is $l$. The individual gives birth to a child after time spell $l^{c}\left(0<l^{c}<l\right)$ has elapsed. Thus, each member of generation $t$ has a single parent in generation $t-l^{c}$, and a single offspring in generation $t+l^{c}$. At each point in time the economy consists, therefore, of a continuum of overlapping generations, each at an age between 0 and $l$. The economy's population size is thus a constant of measure $\mathrm{Nl}$.

During their lifetime, individuals form human capital, work, and procreate. Let an individual spend a portion of his lifetime immediately following birth forming human capital and the complementary portion of his lifetime working. While the acquisition of human capital is costly, as it entails the opportunity cost of forgone wage earnings, it subsequently enhances the individual's productivity, and hence his earnings. Since an individual gives birth to a child after $l^{c}(\geq 0)$ of his lifespan has elapsed, $l^{p} \equiv l-l^{c}$ measures the duration of the overlap between the individual and his child. ${ }^{3,4}$

Let $s_{t}$ represent the time span that an individual of generation $t$ chooses to allocate to human capital formation. Hence the remaining $l-s_{t}$ of the individual's lifespan is allocated to work. Let the cost of forming human capital be a proportion $\lambda$ of the individual's wage. The cost of forming human capital is born by the individual's parent as long as the parent is alive, and by the individual himself through borrowing at the market interest rate if additional human capital is formed past the parent's death. ${ }^{5}$ When the individual reaches the age $l^{c}$, he has a child of his own. That child too is faced with a choice of allocating his lifetime between human capital formation and work, drawing on his parent's support in a manner akin to that

\footnotetext{
${ }^{3}$ Alternatively, it can be assumed that the individual gives birth to a child at a younger age and that the child reaches the human capital formation age only at a point in time that is $l^{c}$ into the individual's life. The years prior to that point in time are immaterial since they do not affect the child's human capital formation decision.

${ }^{4}$ Since our aim is to unravel the pure effect of alternative durations of overlapping on human capital formation, we consider the timing of giving birth, $l^{c}$, as exogenously given.

${ }^{5}$ Our interest in this paper is in human capital formation. We concentrate on the effect of inter vivos transfers on human capital formation and we exclude bequests. While the bequests that individuals receive undoubtedly affect their well being, ordinarily bequests are received at a point in time in individuals' life that is long past their human capital formation years.
} 
described above, that is, up to a duration of $l^{p}$. The amount of human capital (measured in efficiency units of labor) that is available to the individual and supplied by him inelastically, generated by the allocation of time $s_{t}$ to human capital formation, is given by $\varphi\left(s_{t}\right)$ where $\varphi(0)=1 ; \varphi\left(s_{t}\right)>1, \varphi^{\prime}\left(s_{t}\right)>0, \varphi^{\prime \prime}\left(s_{t}\right)<0$ for $s_{t} \in(0, l) ; \lim _{s_{t} \rightarrow 0} \varphi^{\prime}\left(s_{t}\right)=\infty$, and $\lim _{s_{t} \rightarrow l} \varphi^{\prime}\left(s_{t}\right)=0$.

Let $r_{t}$ and $w_{t}$ be the instantaneous interest rate and the instantaneous wage rate at time $t$, respectively. The lifetime income (in present value terms) of a generation $t$ individual who chooses to invest $s$ time in human capital formation, recalling the method of financing described above, is

$V_{t}=\int_{t+s}^{t+l} e^{-r_{\tau}(\tau-t)} \varphi(s) w_{\tau} d \tau-\int_{t+\min \left(s, l^{p}\right)}^{t+s} e^{-r_{\tau}(\tau-t)} \lambda w_{\tau} d \tau-\int_{t+l^{c}}^{t+l^{c}+\min \left(s^{\prime}, l^{p}\right)} e^{-r_{\tau}(\tau-t)} \lambda w_{\tau} d \tau$,

where $s^{\prime}$ is the duration of the human capital formation period chosen by the individual's child. Without loss of generality, ${ }^{6}$ we assume that the individual seeks to maximize his lifetime income, that is,

$$
s_{\mathrm{t}}=\arg \max _{s} V_{t}
$$

Hence, the optimal human capital formation span for an individual of generation $t$ is implicitly given by the first-order condition

$$
\varphi^{\prime}\left(s_{t}\right) \int_{t+s_{t}}^{t+l} e^{-r_{\tau}(\tau-t)} w_{\tau} d \tau=e^{-r_{t+s t} \times s_{t}} w_{t+s_{t}}\left[\varphi\left(s_{t}\right)+\lambda \delta\left(s_{t}-l^{p}\right)\right]
$$

where $\delta(x)=0$ for $x<0, \delta(x)=1$ for $x>0$, and $0 \leq \delta(0) \leq 1$.

We now describe briefly the economy. We have in mind a small economy that operates in a perfectly competitive world in which economic activity extends over an infinite continuous time. At every point in time the economy produces a single consumption good using perfectly durable capital and labor measured in efficiency units in the production process. The supply of capital at each point of time consists of the output that was not consumed in addition to net international borrowing. Capital is perfectly mobile across countries and the rate of return to capital is at a stationary positive level, $\bar{r}$, in terms of the

\footnotetext{
${ }^{6}$ In a more general setting in which the individual maximizes his lifetime utility $\int_{t}^{t+l} e^{-\beta(\tau-t)} u\left(c_{\tau}\right) d \tau$ subject to the budget constraint $\int_{t}^{t+l} e^{-r_{\tau}(\tau-t)} c_{\tau} d \tau \leq V_{t}$, where $u(\cdot)$ is the instantaneous utility function, $c_{\tau}$ is consumption at time $\tau$, and $\beta$ is the discount rate, it is rather straightforward to show that under a constant interest rate and perfectly competitive markets, assumptions to which we resort subsequently, the individual's indirect utility is strictly increasing in his lifetime income $V_{t}$.
} 
consumption good. The supply of labor at each point of time is the sum of the aggregate supply of human-capital-augmented labor of all the generations. Production at each point of time occurs according to a constant returns to scale production function which is invariant across time. Therefore, the output produced at time $t, Y_{t}$, is

$$
Y_{t}=F\left(K_{t}, L_{t}\right) \equiv L_{t} f\left(k_{t}\right) ; \quad k_{t}=K_{t} / L_{t}
$$

where $K_{t}$ and $L_{t}=\int_{\tau+s_{\tau} \leq t} \varphi\left(s_{\tau}\right) N d \tau$ are the capital and labor employed at time $t$, respectively. The production function $f(k)$ is strictly increasing and strictly concave. Producers operate in a perfectly competitive environment. Profit maximization gives rise to the following firstorder conditions

$$
\begin{aligned}
r_{t} & =f^{\prime}\left(k_{t}\right) ; \\
w_{t} & =f(k)-f^{\prime}\left(k_{t}\right) k_{t},
\end{aligned}
$$

where $r_{t}$ and $w_{t}$ are the interest rate and wage rate at time $t$, respectively, and output is the numeraire. Given the unrestricted nature of the international capital markets, the economy's interest rate is exogenously given at the world level $\bar{r}$, at all times. Consequently, the capitallabor ratio employed in production is stationary at a level $\bar{k}$,

$$
\bar{k}=f^{\prime-1}(\bar{r}) \text {, }
$$

and the wage rate is stationary at a level $\bar{w}$,

$$
\bar{w}=f(\bar{k})-f^{\prime}(\bar{k}) \bar{k}
$$

Since the economic environment in which the individual optimizes is stationary, we can ignore time subscripts and rewrite (2) as

$$
\frac{1}{\bar{r}}\left[1-e^{-\bar{r}(l-s)}\right] \varphi^{\prime}(s)=\varphi(s)+\lambda \delta\left(s-l^{p}\right) .
$$

The left-hand side of (8), multiplied by $\bar{w}$, measures the marginal benefit of human capital formation. The right-hand side of (8), multiplied by $\bar{w}$, measures the marginal cost of human capital formation, which has two components. The first component is the usual opportunity cost of forgone earnings and the second component reflects the impact of the overlap between parents and children. When the duration of the period of human capital formation chosen by the individual is shorter than the duration of the overlap, $\delta\left(s-l^{p}\right)=0$; the entire cost of human capital formation is born by the individual's parent and the second component 
vanishes. However, when the individual chooses to form human capital for a time span that is longer than the duration of the overlap with his parent, $\delta\left(s-l^{p}\right)=1$; the marginal cost of forming human capital incorporates the extra cost of financing human capital formation through the marketplace. Given the assumptions concerning the production function of human capital, the solution (8), and the solution to the individual's maximization problem in (1), is unique and interior (that is, the length of time allocated to human capital formation maintains $\left.\mathrm{s}_{\mathrm{t}} \in(0, l)\right)^{7}$

\section{The effect of an extended intergenerational overlap on human capital formation}

Although in this paper we are interested in investigating the consequences of the duration of the overlap between parents and children as measured by $l^{p}$, typically an increase in $l^{p}$ arises from the prolongation of life expectancy $l$. Therefore, a change in $l$ affects the endogenous variables through two channels: changing the life expectancy, and varying the duration of the overlap between parents and children. We are able though to separate the effects of a change in $l$ on the investment in human capital that arises from these two channels. While there are many interesting models that focus on the link between human capital formation and life expectancy (recent examples include Stark, 1999, chapter 2; Kalemli-Ozcan, Ryder, and Weil, 2000; and Leung and Wang, 2003), our investigation of the overlapping-duration channel is novel.

Suppose that there is an increase in $l$. The left-hand side of (8), as a function of $s$, shifts upward: the conventional life-expectancy channel is at work. As a result of the increase in $l$, individuals live longer and hence are able to reap the returns to human capital formation over a longer period, raising the marginal benefit of human capital formation. But the increase in $l$ also increases $l^{p}$ by the same amount (keeping $l^{c}$ constant), which in turn affects the marginal cost of human capital in the right-hand side of (8) in a more subtle way. The righthand side of (8), as a function of $s$, is a smooth function except for a vertical jump that occurs at $s=l^{p}$. Upon an increase in $l^{p}$, the jump in the marginal cost function occurs at a later point in time, thereby extending the range within which the marginal cost of human capital formation is low. This is due to the overlapping-duration channel: a larger $l^{p}$ implies a

\footnotetext{
${ }^{7}$ The second-order condition for a maximum holds: $\frac{1}{\bar{r}}\left[1-e^{-\bar{r}(l-s)}\right] \varphi^{\prime \prime}(s)-\left[1+e^{-\bar{r}(l-s)}\right] \varphi^{\prime}(s)<0$.
} 
longer overlap between parents and children, which in turn allows children to enjoy parental support for forming human capital for a longer period of time. To the extent that the extra parental support lowers the cost of forming human capital at the margin, the overlappingduration channel is operative as it encourages additional human capital formation that would not have been possible had the intergenerational overlap remained the same. In short, while the life-expectancy channel operates from the benefit side, the overlapping-duration channel operates from the cost side. The following figures illustrate circumstances in which the overlapping-duration channel is fully operative.

Suppose that $l$ rises from $l_{1}$ to $l_{2}$, and hence $l^{p}$ rises from $l_{1}^{p}$ to $l_{2}^{p}$. Figure 1 shows that individuals initially choose $s_{1}^{*}<l_{1}^{p}$ for engaging in human capital formation so that their entire investment is paid for by the parents and no market finance takes place. Following the increase of $l$ from $l_{1}$ to $l_{2}$, the marginal benefit curve shifts up due to the life-expectancy effect, and the marginal cost curve extends the range (the darkened segment between $l_{1}^{p}$ and $l_{2}^{p}$ ) within which human capital formation is family financed (the overlapping-duration effect). Consequently, individuals choose $s_{2}^{*}$. Had the cost structure of human capital formation been the same as before (that is, without the overlapping-duration effect), the lifeexpectancy effect alone would have resulted in a duration of human capital formation equal to $l_{1}^{p}$, which is less than $s_{2}^{*}$. Hence the additional period of human capital formation of $s_{2}^{*}-l_{1}^{p}$ can be attributed to the pure effect of the overlapping duration. In Figure 2, individuals initially choose $s_{1}^{*}=l_{1}^{p}$ for human capital formation so that the constraint of parental supported human capital formation just binds. Following an increase of $l$ from $l_{1}$ to $l_{2}$, and of $l^{p}$ from $l_{1}^{p}$ to $l_{2}^{p}$, individuals choose $l_{2}^{p}$. In this case the life-expectancy effect results in a duration of human capital formation that is equal to only $s_{2}^{\prime}$, and the overlappingduration effect contributes to the additional increase of $l_{2}^{p}-s_{2}^{\prime}$ in the duration of human capital formation. Similarly, Figure 3 illustrates the case in which individuals initially choose $s_{1}^{*}>l_{1}^{p}$, relying on market financing above and beyond the overlapping period with their parents. Following the increases in $l$ and $l^{p}$, they choose $l_{2}^{p}$, wherein the overlappingduration effect again contributes to the additional increase of $l_{2}^{p}-s_{2}^{\prime}$ in the duration of human capital formation. 


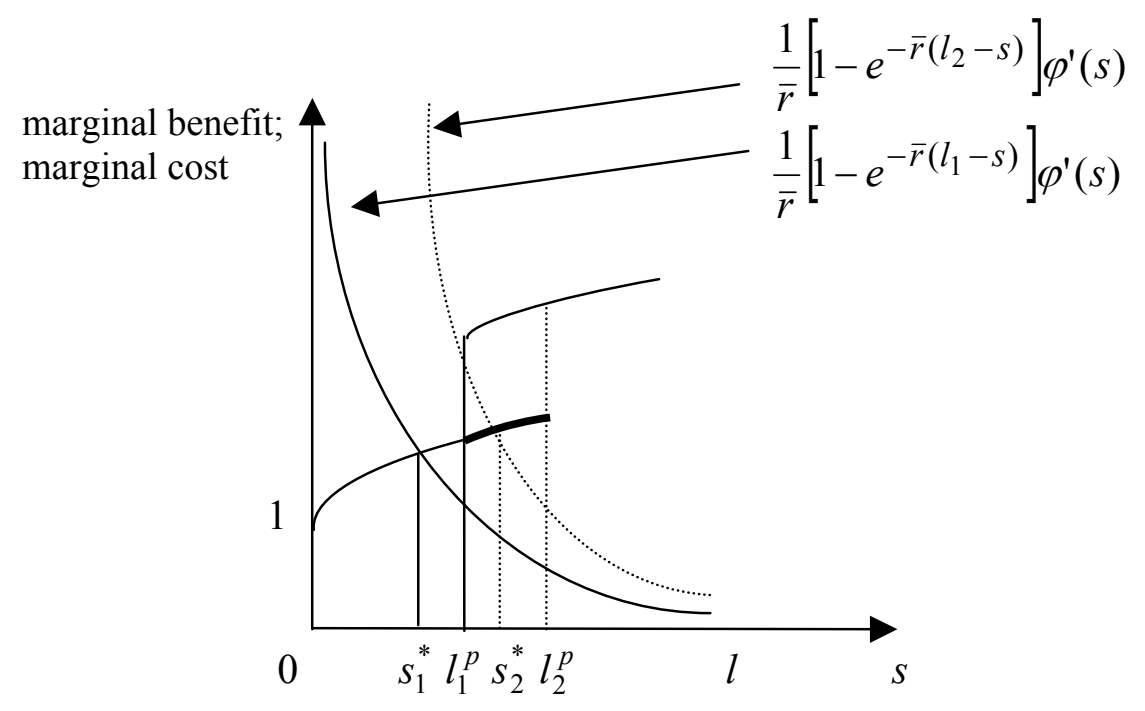

Figure 1

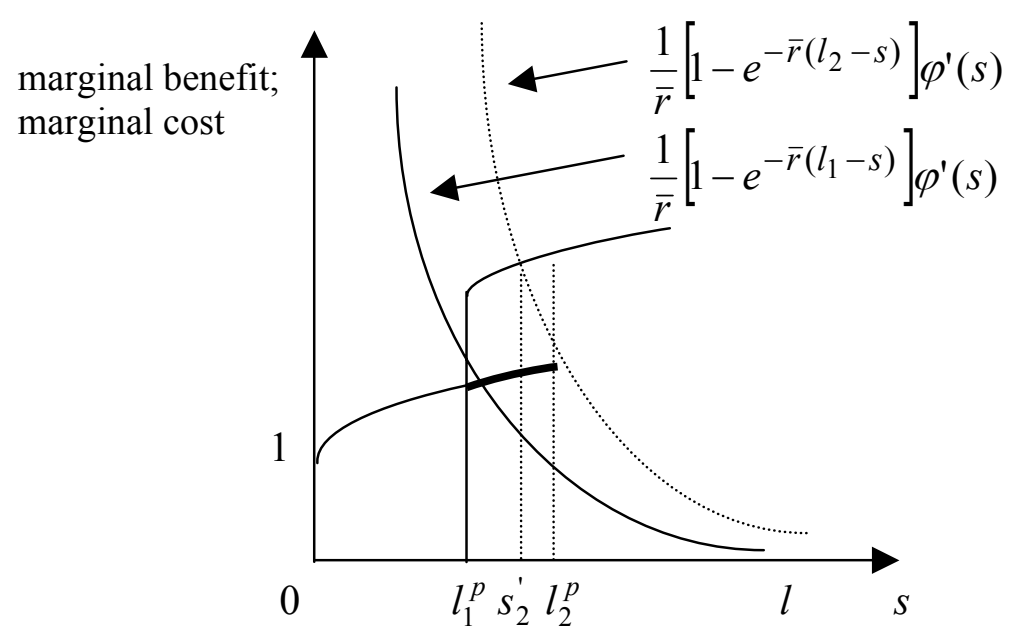

Figure 2

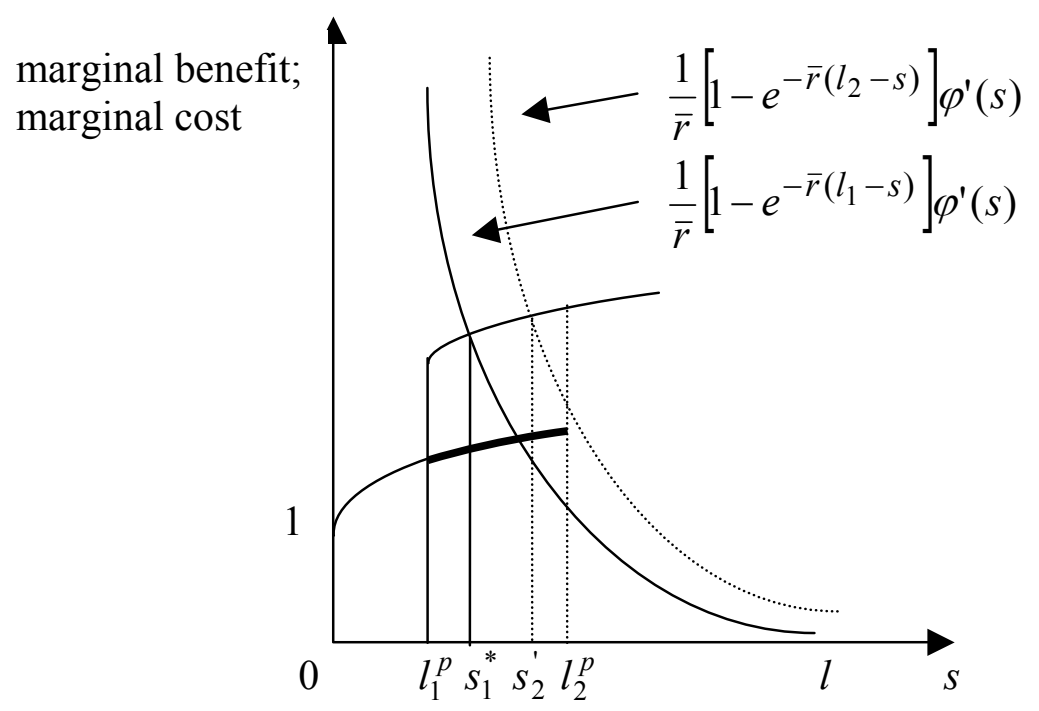

Figure 3 
Having provided a non-exhaustive list of cases in which the overlapping-duration channel is operative in human capital formation decisions, we should add that, of course, the overlapping-duration channel is not always operative. Nonetheless, the combined effect of the life-expectancy channel and the overlapping-duration channel is always positive.

Proposition 1: An increase in $l$ will always lead to an increase in human capital formation, that is, $\frac{\partial s}{\partial l}>0$.

Proof: See appendix.

Our argument so far amounts to a statement that the positive effect of a longer life expectancy on human capital formation arises from two distinct effects: a pure lifeexpectancy effect and a prolonged intergenerational overlapping effect. Yet decomposing an effect into its constituent parts falls short of demonstrating that each part has a life of its own. Thus, we next investigate the pure overlapping-duration effect, studying its role in isolation from, and independently of, the conventional life-expectancy effect.

Suppose that individuals give birth to their children at a somewhat earlier age while their life expectancy remains intact. This change entails an increase in $l^{p}$ that is not associated with a change in $l$. While, by construction, the left-hand side of (8) remains unaltered so that the life-expectancy channel is not operative, the change in $l^{p}$ affects the right-hand side of (8) through the overlapping-duration channel. To illustrate the pure effect of the overlapping duration on human capital formation, suppose that $l^{p}$ increases from $l_{1}^{p}$ to $l_{2}^{p}$ (keeping $l$ constant). To facilitate comparison we consider once again three cases wherein the initial choice of the duration of the human capital formation span is less than, equal to, or greater than the duration of overlap. In Figure 4, individuals initially choose to form human capital for a period that is shorter than the duration of the overlap with their parents, $s_{1}^{*}<l_{1}^{p}$. In this case a prolonged overlapping has no impact on the individuals' decision as to how much human capital to form. In Figure 5, the initial decision is to set the period of human capital formation equal to the duration of the overlap, that is, $s_{1}^{*}=l_{1}^{p}$. In this case, the marginal benefit curve intersects the vertical portion of the marginal cost curve, and the extended overlap has a clear and positive effect - it increases the individuals' human 


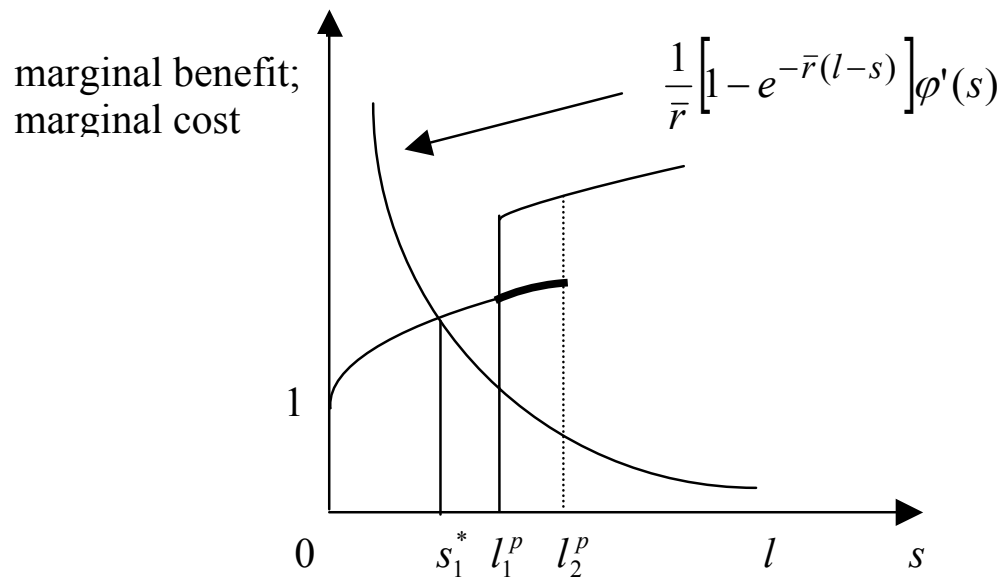

Figure 4

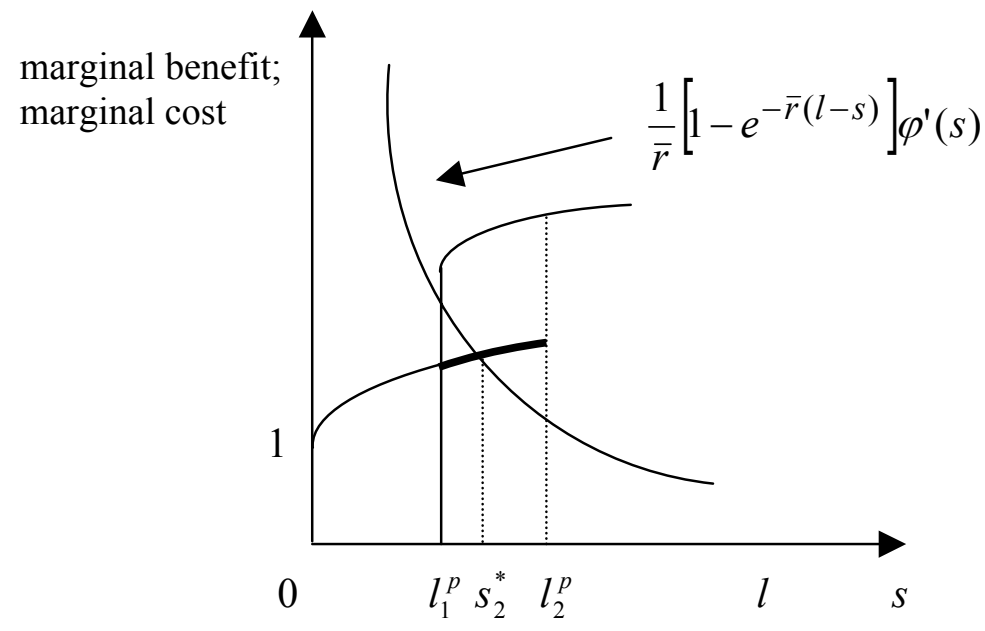

Figure 5

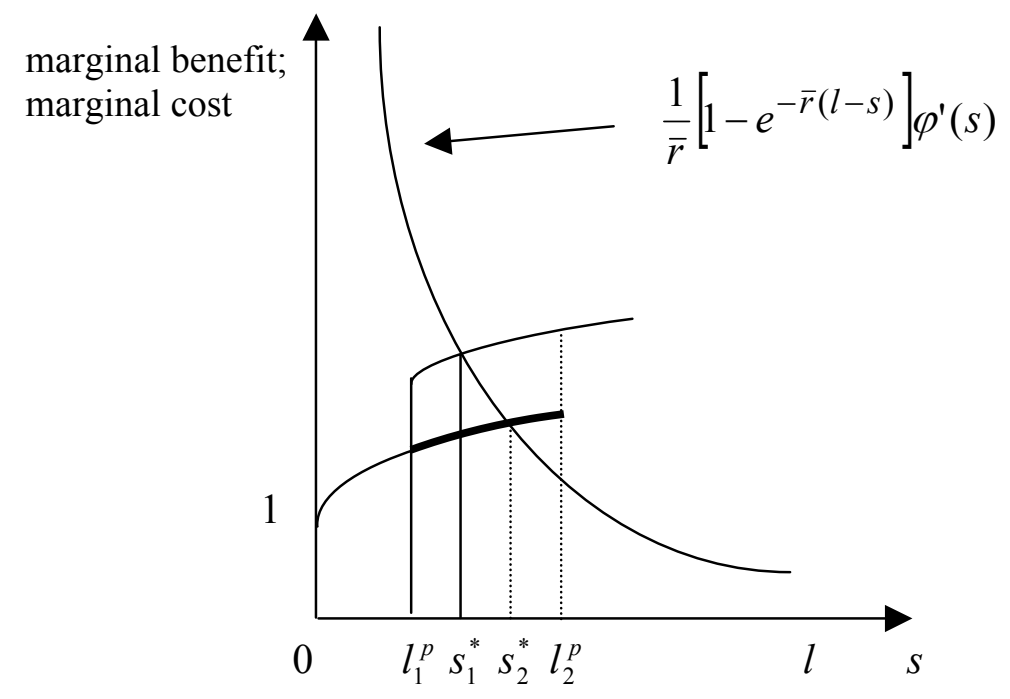

Figure 6 
capital formation period to $s_{2}^{*}{ }^{8}$ Lastly, Figure 6 presents the case where individuals initially choose a duration of human capital formation, $s_{1}{ }^{*}$, that exceeds the duration of the overlap with their parents. The extended overlap prompts additional human capital formation, provided that the increase in the duration of the overlap is large enough (that is, as large as $\left.l_{2}^{p}>s_{1}^{*}\right)$. We summarize these results on the pure effect of overlapping in the following proposition.

Proposition 2: An increase in $l^{p}$ from $l_{1}^{p}$ to $l_{2}^{p}$ without any change in $l$ leads to a strict increase in human capital formation by an individual, that is, $s_{2}^{*}>s_{1}^{*}$, if $s_{1}^{*}=l_{1}^{p}$ or if $l_{1}^{p}<s_{1}^{*}<l_{2}^{p}$.

\section{The welfare effect of an extended intergenerational overlap}

We have shown that the duration of the intergenerational overlap of individuals with their parents can impact positively on an individual's formation of human capital. This channel of influence is independent from the usual repercussion of the life-expectancy channel.

To analyze the welfare effect of an extended overlap both when it operates in conjunction with the life-expectancy effect and when it operates independently of the lifeexpectancy effect, we first calculate the flow of per-capita output. Since at any given point in time the economy's labor input measured in efficiency units is $L=\int_{t-l}^{t-s} \varphi(s) N d \tau=(l-s) \varphi(s) N$, the economy-wide output (given (6)) is $Y=L f(\bar{k})$, and population size is $N l$, per-capita output is:

$$
y=\frac{Y}{N l}=\frac{(l-s) \varphi(s) f(\bar{k})}{l} .
$$

Measuring welfare by the flow of per-capita output in (9), we present our results regarding the welfare implication of an extended intergenerational overlap in the two cases, that is, with and without a simultaneous change in life expectancy, in the following proposition.

\footnotetext{
8 We exclude from consideration the exceptional case in which the marginal benefit curve intersects the marginal cost curve at the lower corner of its vertical portion. In other words, when $s=l^{p}$, we assume that $s$ solves (8) with a $\delta(0)>0$.
} 
Proposition 3: (i) For a given $\Delta l=\Delta l^{p}>0, \Delta y>0$ holds; and (ii) for a given $\Delta l^{p}>0$ but $\Delta l=0, \Delta y>0$ holds as long as $\Delta s>0$. In both cases, $\Delta y$ is larger the larger is $\Delta s$.

Proof: (i) It suffices to show that $\Delta y>0$ for any small increase of $\Delta l$ in both $l$ and $l^{p}$. Total differentiation of (9) yields

$$
\begin{aligned}
\Delta y & =\frac{\left[(\Delta l-\Delta s) \varphi(s)+(l-s) \varphi^{\prime}(s) \Delta s\right] l-(l-s) \varphi(s) \Delta l}{l^{2}} f(\bar{k}) \\
& =\frac{f(\bar{k})}{l}\left(\left[(l-s) \varphi^{\prime}(s)-\varphi(s)\right] \Delta s+\frac{s \varphi(s) \Delta l}{l}\right) .
\end{aligned}
$$

Since $\int_{S}^{l} 1 \cdot d t>\int_{S}^{l} e^{-\bar{r}(t-s)} d t$, or $l-s>\frac{1}{\bar{r}}\left[1-e^{-\bar{r}(l-s)}\right]$ (assuming a positive interest rate $\bar{r}$ ), it follows from (8) that $(l-s) \varphi^{\prime}(s)-\varphi(s)>0$. Since $\Delta s>0$ from Proposition 1, it follows that $\Delta y>0$.

(ii) Since $l$ is constant in this case, denoting $s \equiv s\left(l^{p}\right)$ and differentiating both sides of (9) with respect to $l^{p}$, we have

$$
\frac{d y}{d l^{p}}=\frac{f(\bar{k})}{l}\left[(l-s) \varphi^{\prime}(s)-\varphi(s)\right] s^{\prime}\left(l^{p}\right) .
$$

Hence, for a given $\Delta l^{p}>0$, we obtain

$$
\Delta y=\frac{f(\bar{k})}{l} \int_{l^{p}}^{l^{p}+\Delta l^{p}}\left[(l-s) \varphi^{\prime}(s)-\varphi(s)\right] s^{\prime}\left(l^{p}\right) d l^{p}=\frac{f(\bar{k})}{l} \int_{s}^{s+\Delta s}\left[(l-s) \varphi^{\prime}(s)-\varphi(s)\right] d s .
$$

Again, since it follows from (8) that $(l-s) \varphi^{\prime}(s)-\varphi(s)>0$, it is clear that $\Delta y>0$ as long as $\Delta s>0$.

In both cases, it is easy to see from the expressions of $\Delta y$ that the larger the increase in $s$ that arises from a given increase in $l$ or $l^{p}$, the larger the increase in $y$.

When an extended overlap, resulting from prolonged life expectancy, brings about additional human capital formation as illustrated in Figures 1-3, it also raises the per-capita output at any point in time. Similarly, when an extended overlapping that is not accompanied by a change in life expectancy induces additional human capital formation as illustrated in Figures 5 and 6, it also raises the per-capita output at any point in time. Therefore, whenever the overlapping-duration channel is operative, either in conjunction with the life-expectancy effect or independently of it, an increase in the intergenerational overlap is welfare improving. 
By the same token, a shortening of the overlap between parents and their children can have an adverse impact on human capital formation, and hence on welfare.

Corollary: Consider two identical economies in which the overlapping-duration channel is operative. The economy that experiences an increase in the duration of the overlap will enjoy a higher per-capita output than the economy in which the duration of the overlap remains unchanged.

\section{Complementary reflections}

In a highly stylized economy in which material capital is the only production input, the production function is concave, and the cost of acquiring capital is linear, a lengthening of the lifespan of capital prompts the optimal acquisition of more capital. The pioneers some four decades ago of the modern theory of human capital, notably Jacob Mincer, Theodore W. Schultz, and Gary S. Becker, were duly aware of the powerful analogy between the effect of the lifespan of material capital and the effect of longevity, as a proxy of the length of the period during which human capital renders a return. Yet, while the acquisition of more material capital (machinery) today in response to a lengthened lifespan would presumably crowd out the acquisition of material capital tomorrow, a lengthened life expectancy could crowd in human capital formation by the next generation. Here, the direct analogy between the two types of capital apparently breaks down.

The positive effect on human capital formation of overlapping with a parent arises from the parent's provision of support for the child's formation of human capital. In the absence of any reverse transfer from the child to the parent, the motive for the parental support is altruism. In this paper we assume parental altruism within dynasties rather than explain why and how it evolves - an issue that we address in related work (Falk and Stark, 2001). ${ }^{9,} 10$

While the assumption that the parent provides somewhat less than full support in the child's pursuit of human capital will affect the absolute size of the effects in our model, it will not change its qualitative predictions.

\footnotetext{
9 The extended overlap is tantamount to enhanced altruism, an effect studied in Stark, 1999 chapter 1. There, as here, the effect on the child's wellbeing is positive.

${ }^{10}$ We further assume that parental altruism takes the form of sharing a meal, not imposing a will; parents do not decide for their children how much human capital the children should form.
} 
A widely held view maintains that in developing economies, delayed marriage and postponed childbearing will hasten the pace of economic development and entail a higher per-capita output. The rationale is that as a consequence of delay and postponement, the denominator in the output per capita ratio will be smaller, and the nominator will be larger since adults (young women) will be spending more of their productive time working in the economy rather than tending to home production (rearing children). Yet if the economic environment in which such changes occur is characterized by a fixed (or little-changed) life expectancy, the intergenerational overlap will be reduced, possibly impinging negatively on human capital formation (Proposition 2), and on welfare (Proposition 3).

To discriminate between the received model of human capital formation and the overlapping model, consider a setting in which the life expectancy of the individual's parent is rising (the intergenerational overlap is lengthened) and the individual's life expectancy is declining, yet the individual invests more in human capital formation. Such an outcome can only arise from the operation of the overlapping effect since the individual's negative lifeexpectancy effect (the shortened duration of the payback period to an investment in human capital) implies a reduced investment in human capital. The same discriminating test applies if the life expectancy of the individual's parent is rising, and the individual's life expectancy remains unchanged.

One possibility for assessing empirically the distinct effect of the intergenerational overlap on human capital formation is to examine the age of home leaving and to explore whether this age correlates positively with schooling. A study of the long-term trend in the age of home leaving in the United States (Gutmann, Pullum-Piñon and Pullum, 2001) provides illuminating evidence. The study asks whether young people aged 15-29 were living with one or both of their parents at the time of each of the decennial censuses from 1880 through 1990. The study finds that, with the exception of the Second World War era (and in contrast to widely-held views), the age of leaving home rose in twentieth century America. The study further suggests that a reason for leaving home early is the death of the parents and it points out that over the century, there was a dramatic decline in the likelihood of becoming an orphan between the ages of 15 to 29 , a change brought about by the steady decline in adult mortality. In addition, the study highlights the sharply increased likelihood of attendance of high school by those aged 15-19, "and with it the likelihood that they would live at home" (p. 10). Thus, the long-term trends that the study depicts are that the age at which young people 
ceased to live with their parents rose, adult mortality declined, and schooling and higher education - especially in the form of community colleges - increased.

Within the field of the economics of human capital formation, there has long been a debate concerning the causal relationship between education and health (with age being the most important component of health). Many empirical studies have shown that there is a positive correlation between education and health. However, the source of this correlation is not clear. It has been suggested that the observed correlation is caused by a third variable that is correlated both with education and with health (Grossman and Kaestner, 1997; Grossman, 2000). The duration of the intergenerational overlap could constitute the elusive variable.

If the poor in an economy overlap with their children for a shorter time span than do the rich, the children of the poor will run out of parental support earlier than the children of the rich, and could therefore acquire less human capital even if all children have access to equally priced market finance. Thus, rendering the terms under which children from poor families can borrow in order to pay for their acquisition of human capital equal to the terms under which children from rich families can so borrow may not equalize the investment in human capital environment for the two types of children under differential overlapping.

A low likelihood that a costly human capital formation today will be rewarded by a flow of returns tomorrow dampens investment in human capital. Among the considerations that impinge on this likelihood is the risk to life emanating from civil strife. It is less appreciated though that the probability that civil strife will occur is negatively affected by the level of investment in human capital: people who stand to lose a large quantity of human capital are less inclined to resort to violent means of settling disputes and resolving conflicts than people who risk only meager quantities of human capital. To the extent that an extended overlap entails the formation of a larger quantity of human capital, the duration of the overlap will be correlated negatively with the likelihood of civil strife or with the likelihood of brutality. 


\section{Appendix}

Proof of Proposition 1: We first consider the case where either $s<l^{p}$ or $s>l^{p}$, and then the case where $s=l^{p}$.

If either $s<l^{p}$ or $s>l^{p}$, that is, the marginal benefit curve intersects the marginal cost curve either at its lower portion before the jump (recall Figure 1), or at its upper portion after the jump (recall Figure 3), the second term in the right-hand side of (8) is constant. Hence, from differentiating both sides of (8) with respect to $l$ :

$$
e^{-\bar{r}(l-s)}\left(1-\frac{\partial s}{\partial l}\right) \varphi^{\prime}(s)+\frac{1}{\bar{r}}\left[1-e^{-\bar{r}(l-s)}\right] \varphi^{\prime \prime}(s) \frac{\partial s}{\partial l}=\varphi^{\prime}(s) \frac{\partial s}{\partial l},
$$

which implies that $\frac{\partial s}{\partial l}=\frac{e^{-\bar{r}(l-s)} \varphi^{\prime}(s)}{A}$, where

$$
A=\left[1+e^{-\bar{r}(l-s)}\right] \varphi^{\prime}(s)-\frac{1}{\bar{r}}\left[1-e^{-\bar{r}(l-s)}\right] \varphi^{\prime \prime}(s)>0 .
$$

Thus, $\frac{\partial s}{\partial l}>0$ for both $s<l^{p}$ and $s>l^{p}$.

Considering now the case where $s=l^{p}$, we prove, by contradiction, that $\Delta s>0$ for a given $\Delta l=\Delta l^{p}>0$. Suppose this is not true so that $\Delta s \leq 0$ for a given $\Delta l=\Delta l^{p}>0$. Since $s=l^{p}$, we obtain from (8) that

$$
\frac{1}{\bar{r}}\left[1-e^{-\bar{r}(l-s)}\right] \varphi^{\prime}(s)=\varphi(s)+\lambda \delta(0),
$$

where $\delta(0) \geq 0$. Let $l_{1}=l+\Delta l(>l), \quad l_{1}^{p}=l^{p}+\Delta l^{p}\left(>l^{p}\right)$, and $s_{1}=s+\Delta s(\leq s)$. It then follows that $s_{1}<l_{1}^{p}$ and hence, after the increases in $l$ and $l^{p},(8)$ becomes

$$
\frac{1}{\bar{r}}\left[1-e^{-\bar{r}\left(l_{1}-s_{1}\right)}\right] \varphi^{\prime}\left(s_{1}\right)=\varphi\left(s_{1}\right)
$$

But, because $\varphi(\cdot)$ is an increasing and concave function, the following inequality also holds:

$$
\frac{1}{\bar{r}}\left[1-e^{-\bar{r}\left(l_{1}-s_{1}\right)}\right] \varphi^{\prime}\left(s_{1}\right)>\frac{1}{\bar{r}}\left[1-e^{-\bar{r}(l-s)}\right] \varphi^{\prime}(s)=\varphi(s)+\lambda \delta(0) \geq \varphi\left(s_{1}\right) .
$$

The apparent contradiction completes the proof. 


\section{References}

Falk, Ita and Stark, Oded. 2001. "Dynasties and Destiny: The Roles of Altruism and Impatience in the Evolution of Consumption and Bequests." Economica, 68, 505-518.

Grossman, Michael. 2000. "The Human Capital Model." In Culyer, Anthony J. and Newhouse, Joseph P. (eds.), Handbook of Health Economics. Amsterdam: NorthHolland, 347-408.

Grossman, Michael and Kaestner, Robert. 1997. "Effects of Education on Health." In Behrman, Jere R. and Staccy, Nevzer (eds.), The Social Benefits of Education. Ann Arbor: University of Michigan Press, 69-123.

Gutmann, Myron P., Pullum-Piñon, Sara M. and Pullum, Thomas W. 2001. "Three Eras of Young Adult Home Leaving in Twentieth-Century America." Manuscript, University of Texas at Austin, Texas.

Kalemli-Ozcan, Sebnem, Ryder, Harl and Weil, David. 2000. "Mortality Decline, Human Capital Investment, and Economic Growth.” Journal of Development Economics, 62, 123.

Leung, Chi Ming Michael and Wang, Yong. 2003. "Endogenous Health Care, Life Expectancy, and Economic Growth.” Manuscript, City University of Hong Kong, Hong Kong.

Stark, Oded. 1999. "Altruism and Beyond: An Economic Analysis of Transfers and Exchanges Within Families and Groups." Cambridge: Cambridge University Press. 
Authors: Oded Stark, Yong Wang

Title: The Intergenerational Overlap and Human Capital Formation

Reihe Ökonomie / Economics Series 152

Editor: Robert M. Kunst (Econometrics)

Associate Editors: Walter Fisher (Macroeconomics), Klaus Ritzberger (Microeconomics)

ISSN: $1605-7996$

(C) 2004 by the Department of Economics and Finance, Institute for Advanced Studies (IHS),

Stumpergasse 56, A-1060 Vienna • 
ISSN: 1605-7996 